\title{
The roles of polyethersulfone and polyethylene glycol additive on nanofiltration of dyes and membrane morphologies
}

\author{
Abdul Rahman Hassan ${ }^{1,2^{\dagger}}$, Sabariah Rozali ${ }^{1}$, Nurul Hannan Mohd Safari ${ }^{1}$, Badrul Haswan Besar ${ }^{1}$ \\ ${ }^{1}$ East Coast Environmental Research Institute (ESERI), Universiti Sultan Zainal Abidin, Gong Badak Campus, 21300, Kuala Nerus, Terengganu, Malaysia \\ ${ }^{2}$ Faculty of Industrial Design and Technology (FRIT), Universiti Sultan Zainal Abidin, Gong Badak Campus, 21300 Kuala Nerus, Terengganu, Malaysia
}

\begin{abstract}
In this study, the effects of polymer concentration and additive in the formation of asymmetric nanofiltration (NF) membrane were evaluated. The membrane fabrication was carried out via dry/wet phase inversion technique. A new formulation of dope solution with polymer concentration ranging between $17 \mathrm{wt} \%$ to $21 \mathrm{wt} \%$ and the present of additive was developed. The results show that the permeate flux gradually decreases as polymer concentration increased, until $2.5969 \mathrm{~L} / \mathrm{m}^{2} \mathrm{~h}$ and increased the rejection up to $98.7 \%$. Addition of additive, polyethylene glycol 600 increased dyes rejection up to $99.8 \%$ and decreased the permeate flux to $3.6501 \mathrm{~L} / \mathrm{m}^{2} \mathrm{~h}$. This indicates that the addition of polyethylene glycol additive led towards better membrane performance. The morphological characteristics of NF membrane were analysed using a Scanning Electron Microscopy.
\end{abstract}

Keywords: Additive, Dyes removal, Nanofiltration, Polymer concentration, Wastewater

\section{Introduction}

Dyes are mostly used in many applications such as textile, printing, paper, food, and cosmetics as a colorant for the final products. However, dyes usage has been contributed to environmental pollution and health hazard. Nowadays, it is approximately about 700,000 metric tons of dyes are generated annually around the world $[1,2]$. Since dyes wastewater has become the major effect on the environment, the used of new materials is a challenge in the membrane development process. The utilization of nanofiltration (NF) membrane has increased rapidly according to various applications although it is a relatively new type of the separation process. In wastewater treatment, membrane separation process was known to be among the most promising technology which offered an economical and environmentally approach. It has introduced a new perspective for the treatment of industrial effluents as well as industrial wastewater [3].

Having properties that combine size and electrical effects, NF membranes have solution-diffusion mechanism as present in the ultrafiltration, as those typically ruling transport in non-porous reverse osmosis membranes. NF membranes have pores

This is an Open Access article distributed under the terms of the Creative Commons Attribution Non-Commercial License (http://creativecommons.org/licenses/by-nc/3.0/) which permits unrestricted non-commercial use, distribution, and reproduction in any medium, provided the original work is properly cited.

Copyright (C) 2018 Korean Society of Environmental Engineers typically near $1 \mathrm{~nm}$ in diameter and have fixed charges developed by dissociation groups have been used in the textile effluent treatment to lower the concentration of dyes. The results show that the NF membrane can promote the complete decolorization of effluent. According to the characteristics, NF membranes can retain multivalent complex ions and transfer small uncharged solutes and low charged ions [4, 5]. Moreover, steric hindrance and membrane solute interactions become the factors for the separation occurred in the NF membranes. Steric hindrance and non-electrostatic membrane-solute interactions were the main effects of the retention of uncharged molecules where their transport was taken over by convection due to a pressure difference and diffusion at different concentration gradient across the membranes [6].

In membrane separation process, most of the polymeric membranes have been prepared by phase inversion process. A homogeneous polymer solution is cast as a thin film or a hollow fiber shape and immersed into a coagulation bath. Between casting solution and non-solvent, the diffusional exchange of solvent and non-solvent can make the casting solution phase-separate to form a membrane with a symmetric or asymmetric structure. Addition of proper additive to the casting solution or the gelation

Received January 10, 2018 Accepted March 10, 2018

${ }^{\dagger}$ Corresponding author

Email: rahmanhassan@unisza.edu.my

Tel: +60-9-668-8069 Fax: +60-9-668-8707

ORCID: 0000-0002-9857-5747 
media, introducing additional steps and coupling chemical reaction with phase separation process might give the right membrane properties. Surfactants, polymer, mineral fillers and non-solvents are examples of additives that have been used in casting solution during the preparation of polymer solution. The importance of these additives is to suppress and enhance the formation of macrovoids, enhance pore formation and improve pore interconnectivity and/or hydrophilicity [7].

Hence, the main goal of this study is to investigate the effect of polymer concentration and additive on permeate fluxes, dyes rejection, and morphology in polymeric phase inversion asymmetric NF membrane. The experiment has been conducted under the different experimental condition and the performance in term of morphology structures are characterized by using Scanning Electron Microscopy (SEM).

\section{Materials and Methods}

\subsection{Chemical Materials}

Polyethersulfone (PES) supplied by SOLVAY Advanced Polymer Company (RADEL A-300) was used as polymer materials. As a solvent, N-Methyl-2-Pyrrolidone (NMP) with analytical purity of 99.5\% was purchased from Merck. The additive, Polyethylene Glycol (PEG 600) supplied by Merck. Ethanol and n-hexane both were purchased from Merck and used as the coagulation bath in membrane fabrication. Methyl Violet, Methyl Blue and Acid Orange 74 that has been used as synthetic dyes were purchased from Blulux Laboratory Reagents, Merck and Sigma-Aldrich.

\subsection{Formulation of Polymer Solution}

In general, a formulation of polymer solution contained of polymer, solvent, and non-solvent though sometime the addition of polymeric additive was preferred which can be known as multicomponent casting formulation. The multicomponent dope formulations are summarized in Table 1 below. In making polymer solution, PES was first dried for at least $1 \mathrm{~d}$ in a vacuum oven at a temperature of about $100 \pm 2^{\circ} \mathrm{C}$ to leach out all water vapour. Firstly, the solvent and water were poured into the round bottom flask until the temperature increase to $50-60^{\circ} \mathrm{C}$. When the temperature has reached $50^{\circ} \mathrm{C}$, PES was added gradually until the entire polymer was dissolved before an additive was added. The solution was being stirred for $1 \mathrm{~h}$ and surfactant was added $3 \mathrm{~h}$ before the polymer solution was completely done.

Table 1. Dope Formulations

\begin{tabular}{cccc}
\hline Membranes & PES (wt\%) & NMP (wt\%) & PEG (wt\%) \\
\hline MO1 & 17 & 83 & 0 \\
MO2 & 19 & 81 & 0 \\
MO3 & 21 & 79 & 0 \\
M1 & 17 & 78 & 5 \\
M2 & 19 & 76 & 5 \\
M3 & 21 & 74 & 5 \\
\hline
\end{tabular}

\subsection{Membrane Fabrication and Casting}

In this study, asymmetric nanofiltration-surfactant (NFS) membrane was fabricated at room temperature $\left(30 \pm 2{ }^{\circ} \mathrm{C}\right)$ with a variation of the polymer solution, ranging from $17 \mathrm{wt} \%$ to 21 wt\%. The casting process was conducted as a small drop of the polymer solution was poured onto a glass plate. The glass plate was used as a support layer while casting knife was fixed at $150 \mu \mathrm{m}$ at an appropriate casting rate (5-10 s). Subsequently, the fabricated membranes were immersed in a water bath for $24 \mathrm{~h}$ for coagulation process occurred before the membranes remained in ethanol for $1 \mathrm{~d}$. Finally, the membranes were soaked in $\mathrm{n}$-hexane for 2-3 $\mathrm{h}$ and kept at room temperature to remove residual organic compounds for $1 \mathrm{~d}$ before they are ready to be used.

\subsection{Experimental Analysis}

NF permeation test was conducted by using a simple permeation cell. Each membrane was subjected to be pressurized for compaction. The passages of the first $10 \mathrm{~mL}$ permeate was collected for analysis. Fig. 1 showed the schematic diagram of the experimental setup. The volume flux was calculated as below:

$$
J=\left(\frac{V}{A t}\right)
$$

where $J$ permeate flux $\left(\mathrm{L} / \mathrm{m}^{2} \mathrm{~h}\right), V$ is the volume of permeate solution collected (L), $A$ is the effective membrane area $\left(\mathrm{m}^{2}\right)$ and $t$ is time (h). $400 \mathrm{kPa}$ was chosen as operating pressure in order to study the effect of dyes rejection. Permeation flux test of dyes was carried out using different types of dyes (methyl violet, methyl blue, and acid orange) at three different concentrations (10 ppm,15 ppm and $20 \mathrm{ppm}$ ) before the rejection was calculated as follows:

$$
R=\left(1-\frac{C p}{C f}\right) \times 100 \%
$$

where $R$ is the rejection (\%), $C p$ and $C f$ are the concentration permeate $(\mathrm{mg} / \mathrm{mL})$ and concentration feed $(\mathrm{mg} / \mathrm{mL})$, respectively. The experimental works were conducted with three times of analysis for triplication and all the experimental data of fluxes and rejection are the average values on the membranes performance.

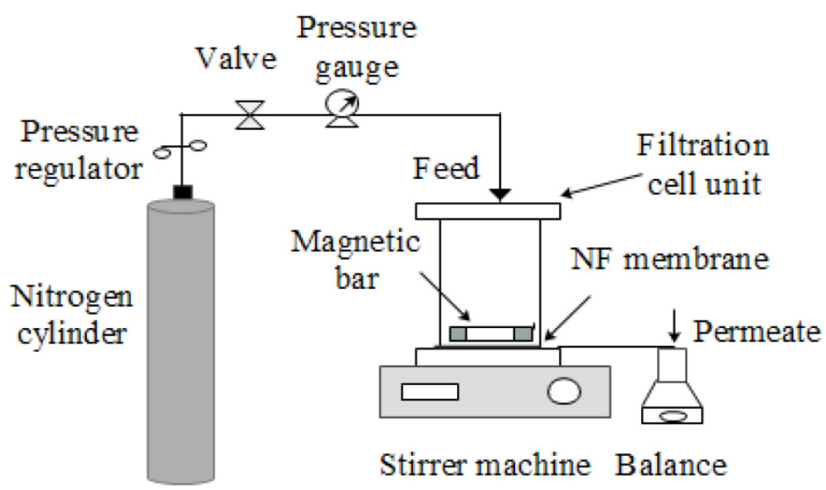

Fig. 1. Schematic diagram of NF permeation rig. 


\subsection{Scanning Electron Microscopy (SEM)}

Properties of the morphology for the fabricated membranes were analyzed by microscopic observation, scanning electron microscope (SEM- JEOL JSM-6360LA). SEM provides the visual information of the cross-sectional morphology and also the top surface of the membranes. Its images were taken under magnification ranging from $700 \mathrm{X}$ to $4000 \mathrm{X}$. The membranes samples were dipped into liquid nitrogen and then coated with gold by using Auto Fine Coater (JFC-1600). The structural morphologies and membranes pores in terms of pore length, pore width were measured by an application supported by SEM.

\section{Results and Discussion}

\subsection{Effects of Polymer Concentration on Performance}

Fig. 2 shows the effect of polymer concentration on permeate flux and rejection of Methyl violet at three different dye concentrations. $10 \mathrm{ppm}$ of dye solution shows the highest flux among other concentrations. However, the permeate flux keeps decreasing as polymer concentration increase from $8.9901 \mathrm{~L} / \mathrm{m}^{2} \mathrm{~h}$ to $4.3245 \mathrm{~L} / \mathrm{m}^{2} \mathrm{~h}$. The rejection of $10 \mathrm{ppm}$ of Methyl violet shows that as polymer concentration increase, the rejection will increase from $71 \%$ to $81 \%$. At $8.7864 \mathrm{~L} / \mathrm{m}^{2} \mathrm{~h}$, MO1 can reject only $33.3 \%$ of dye color for $15 \mathrm{ppm}$ of Methyl violet. Since polymer concentration also plays an important role in this study, the color rejection of Methyl violet increases sharply to $82.9 \%$. As dye concentration increase, the permeate flux keeps decreasing to $2.9318 \mathrm{~L} / \mathrm{m}^{2} \mathrm{~h}$. However, at $20 \mathrm{ppm}$ of Methyl violet, MO1 to MO3 resulted in the same rejection of about 50\%. This finding provides evidence that in NF membrane process, concentration plays an important role to determine the level of performance of the prepared membranes. As can be seen in Fig. 2, permeate flux always higher at lower polymer concentration and decreasing gradually when polymer concentration increase, as well as Methyl violet concentration increases.

Fig. 3 shows experimental data of permeate flux and removal of Methyl blue using NF membrane at different polymer
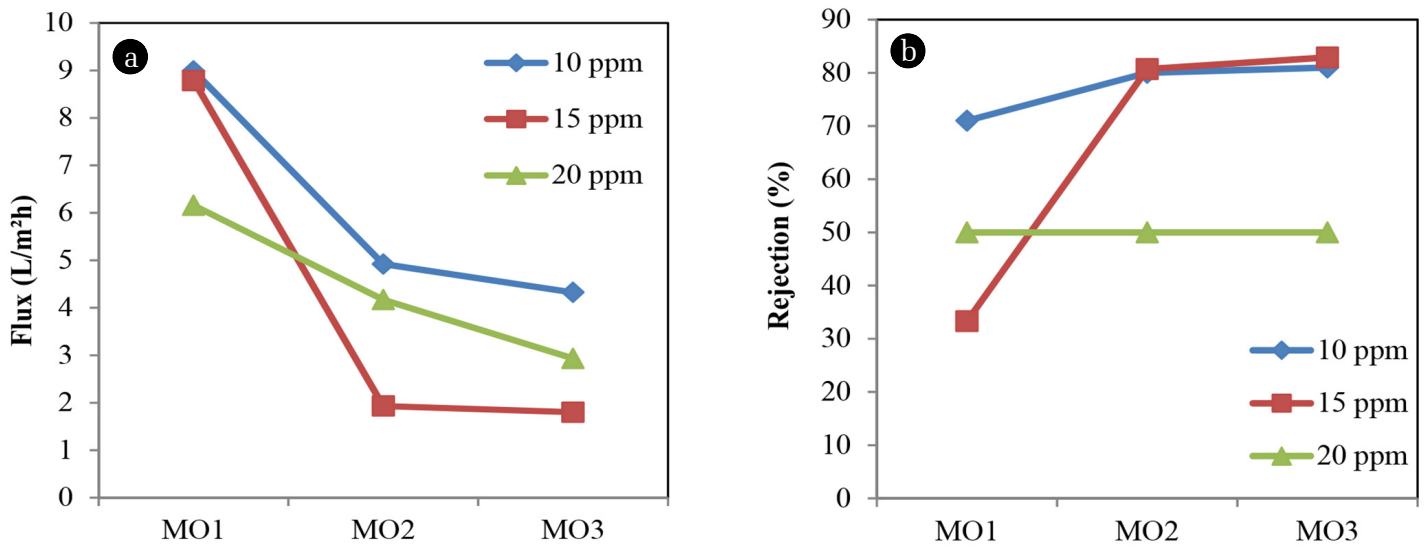

Membranes

Fig. 2. (a) Permeation flux; (b) Percentage of rejection of Methyl violet dye.
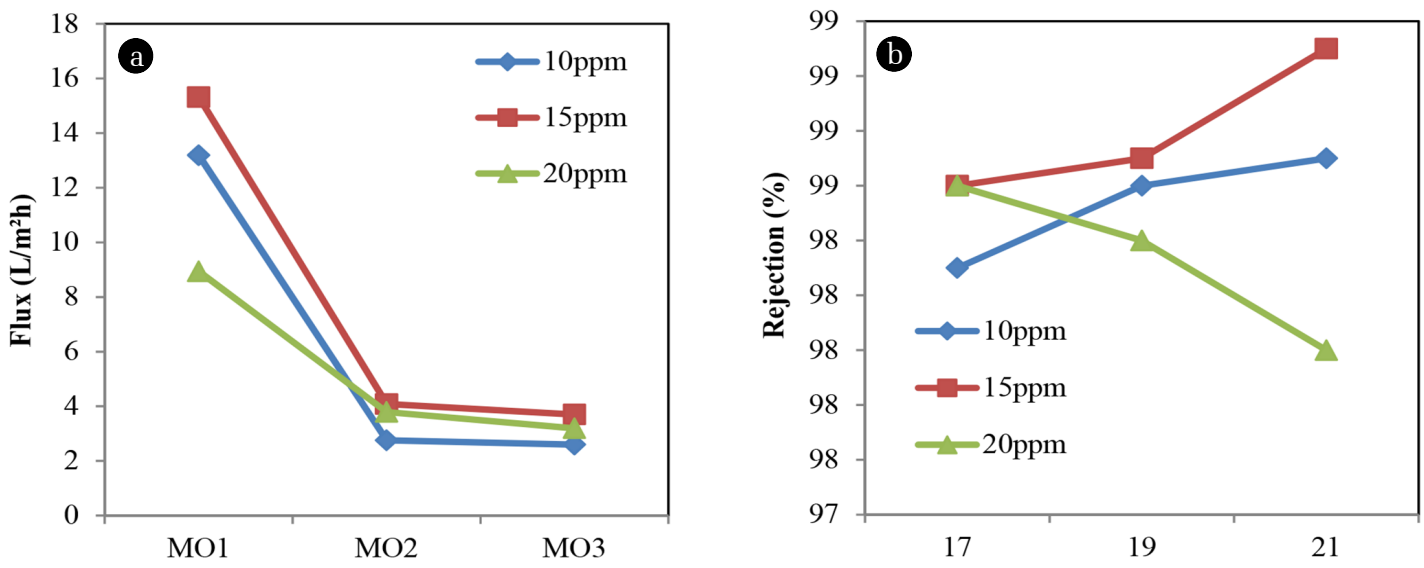

Membranes

Fig. 3. (a) Permeation flux; (b) Percentage rejection of Methyl blue dye.

\section{Membranes}




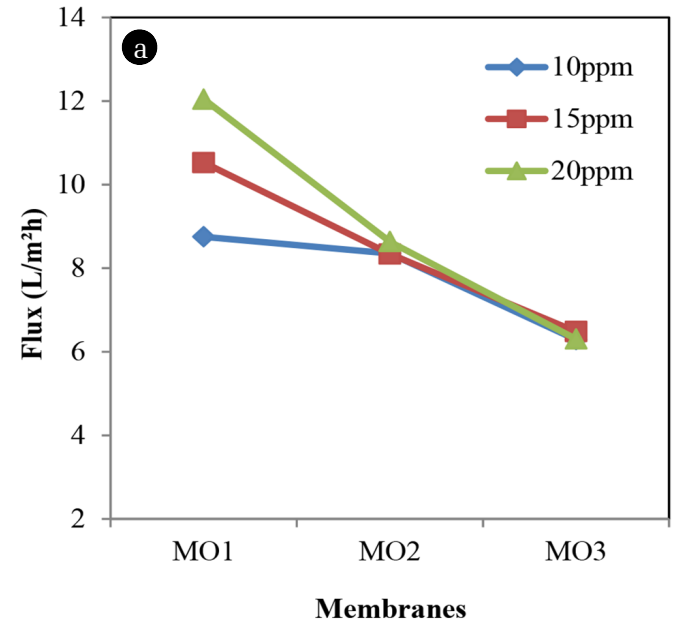

Fig. 4. (a) Permeate flux; (b) Percentage rejection of Acid orange dye.

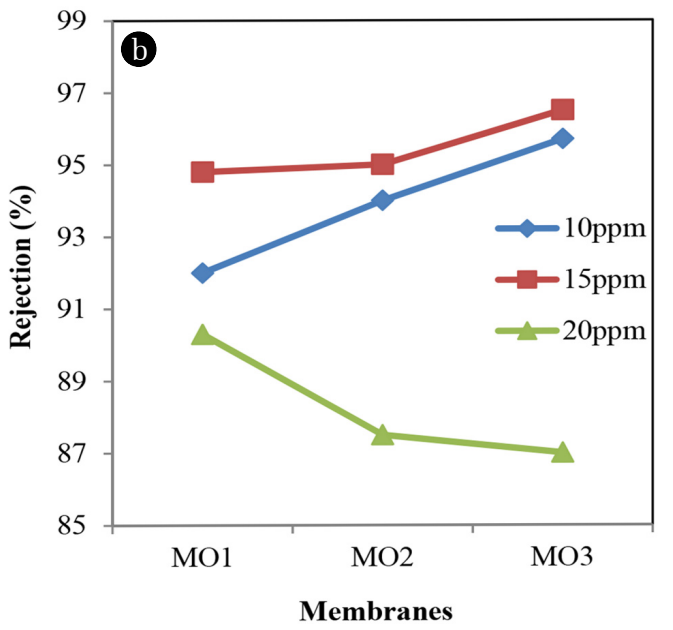

crease the percentage. Other than that, morphological structure of membrane also affects the membrane performance in terms of numbers of pores, finger-like substructure and support layer that helps the movements of molecule throughout the membrane.

\subsection{Effects of Addition of Additive on Performance}

For further study on the performance of NF membrane with the addition of additives, Methyl violet was used prior to test as shown in Fig. 5(a) and (b). Since 10 ppm Methyl violet is the least dye concentration, it always gives the higher permeation flux among others concentration of about 14.3149 $\mathrm{L} / \mathrm{m}^{2} \mathrm{~h}$ at the lower polymer concentration. As polymer concentration increase, the permeation flux of $10 \mathrm{ppm}$ Methyl violet decrease to $8.2376 \mathrm{~L} / \mathrm{m}^{2} \mathrm{~h}$ and rejection gradually increase to $70 \%$.

The result of Methyl violet testing would be different for $15 \mathrm{ppm}$ dye concentration where the permeation flux increases as well as rejection. This is due to the changes in membrane structures that lead to the high permeation flux and high rejection of Methyl violet. M1 was observed to have $11.1223 \mathrm{~L} / \mathrm{m}^{2} \mathrm{~h}$ of permeation flux and have a low rejection of about $33.3 \%$. The rejection of this dye concentration increases sharply up to $80 \%$ when polymer concentration increases. When polymer concentration increase, the permeation flux of $20 \mathrm{ppm}$ Methyl violet decrease from $8.9901 \mathrm{~L} / \mathrm{m}^{2} \mathrm{~h}$ to $2.8852 \mathrm{~L} / \mathrm{m}^{2} \mathrm{~h}$ and rejection was increase from $71 \%$ to $81 \%$.

Fig. 6(a) and (b) presents the experimental data that have been done in terms of permeation flux and percentage rejection of Methyl blue. With $799.81 \mathrm{~g} / \mathrm{mol}$ molecular weight, Methyl blue seems can reject almost $100 \%$ of dye content. At 14.1820 $\mathrm{L} / \mathrm{m}^{2} \mathrm{~h}, 10 \mathrm{ppm}$ of Methyl blue rejects almost $99.2 \%$ of dye contents. This shows that at low dye concentration and low polymer concentration, membrane surface of M1 is thinner so that it can reject a high percentage of dyes.

As dye concentration increase, permeation flux of M1 drop to $6.6619 \mathrm{~L} / \mathrm{m}^{2} \mathrm{~h}$. However, there is no significance decreasing 


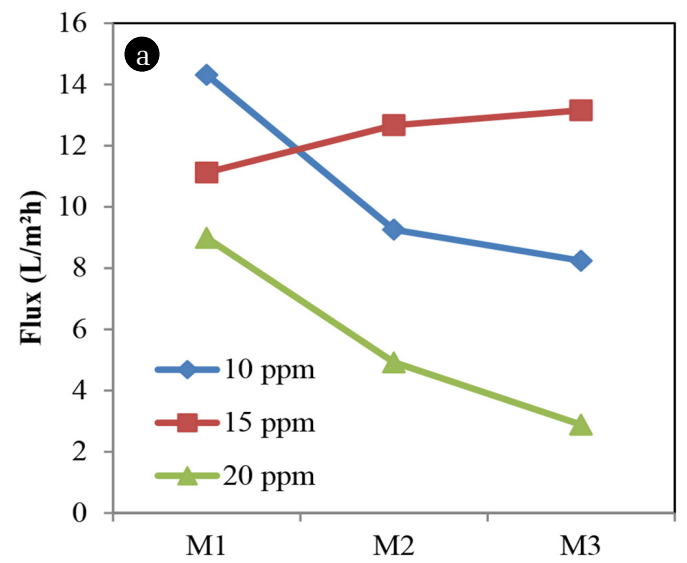

Membranes

Fig. 5. (a) Permeation flux; (b) Percentage rejection of Methyl violet dye.

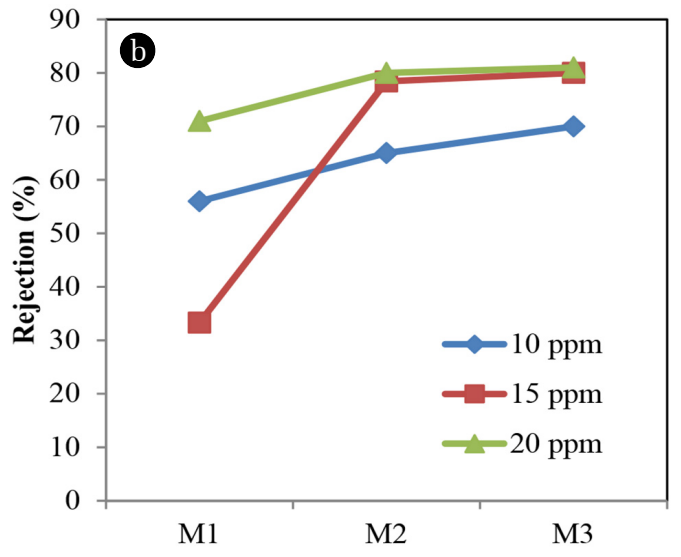

Membranes

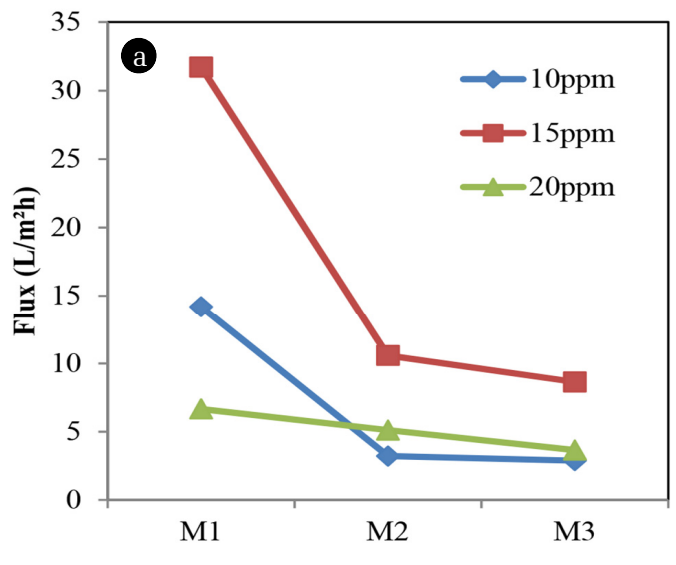

Membranes

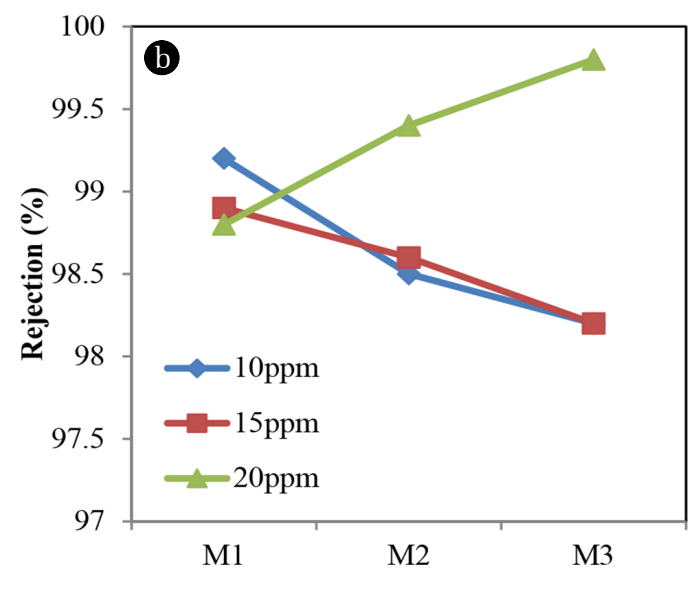

Membranes

Fig. 6. (a) Permeation flux; (b) Percentage rejection of Methyl blue dye.

in rejection where 20 ppm rejects almost 98.8\%. Moreover, experimental also revealed that, as polymer concentration increase, the permeation flux would decrease. From M1 to M3, the permeation flux of $15 \mathrm{ppm}$ dye concentration decrease from 31.7234 $\mathrm{L} / \mathrm{m}^{2} \mathrm{~h}$ to $8.6432 \mathrm{~L} / \mathrm{m}^{2} \mathrm{~h}$. Rejection of $15 \mathrm{ppm}$ dye concentration also shows a decrease about $0.7 \%$ from $98.9 \%$ to $98.2 \%$. This shows that, when polymer concentration increases, the percentage rejection is not affected well. With the addition of the additive, M2 shows increasing of permeation flux for $20 \mathrm{ppm}$ dye concentration from $3.791 \mathrm{~L} / \mathrm{m}^{2} \mathrm{~h}$ to $5.114 \mathrm{~L} / \mathrm{m}^{2} \mathrm{~h}$. This revealed that the efficiency of pore forming additives in changing the membrane properties.

Furthermore, experimental data in Fig. 6 shows that, at 20 ppm dye concentration, the permeate flux was decreased to $3.6501 \mathrm{~L} / \mathrm{m}^{2} \mathrm{~h}$. A researcher has discovered in his study that concentration plays important aspects in NF membrane [8]. Yet, at $20 \mathrm{ppm}$ dye concentration, rejection of Methyl blue keep increasing up to $99.8 \%$ which indicate the complete separation of dye compounds from dye solutions.
Fig. 7(a) and (b) illustrate the permeate flux and percentage rejection of acid orange respectively. At $22.9721 \mathrm{~L} / \mathrm{m}^{2} \mathrm{~h}$, M1 at $10 \mathrm{ppm}$ dye concentration gives rejection of about $91.2 \%$. As polymer concentration increase, the rejection increase up to $94.5 \%$ while permeate flux decreased up to $8.6461 \mathrm{~L} / \mathrm{m}^{2} \mathrm{~h}$. Moreover, as dye concentration increase, Acid orange shows a decrease of permeate flux as well as rejection. M3 shows permeate flux of about $3.9776 \mathrm{~L} / \mathrm{m}^{2} \mathrm{~h}$ and rejection of about $92.8 \%$. Besides, this phenomenon might due to the concentration polarization and osmotic pressure that leads to fouling on the membrane surface and cause the decreasing of permeate flux and increasing in dye rejection [9]. Thus, the study has proven that using a high concentration of Acid orange resulted in decreasing of permeate flux and increase the rejection up to $95.7 \%$.

\subsection{Morphological Study}

As shown in Fig. 8(a), it can be seen that an asymmetric NF membrane consists of dense top layer, finger-like structure, and 

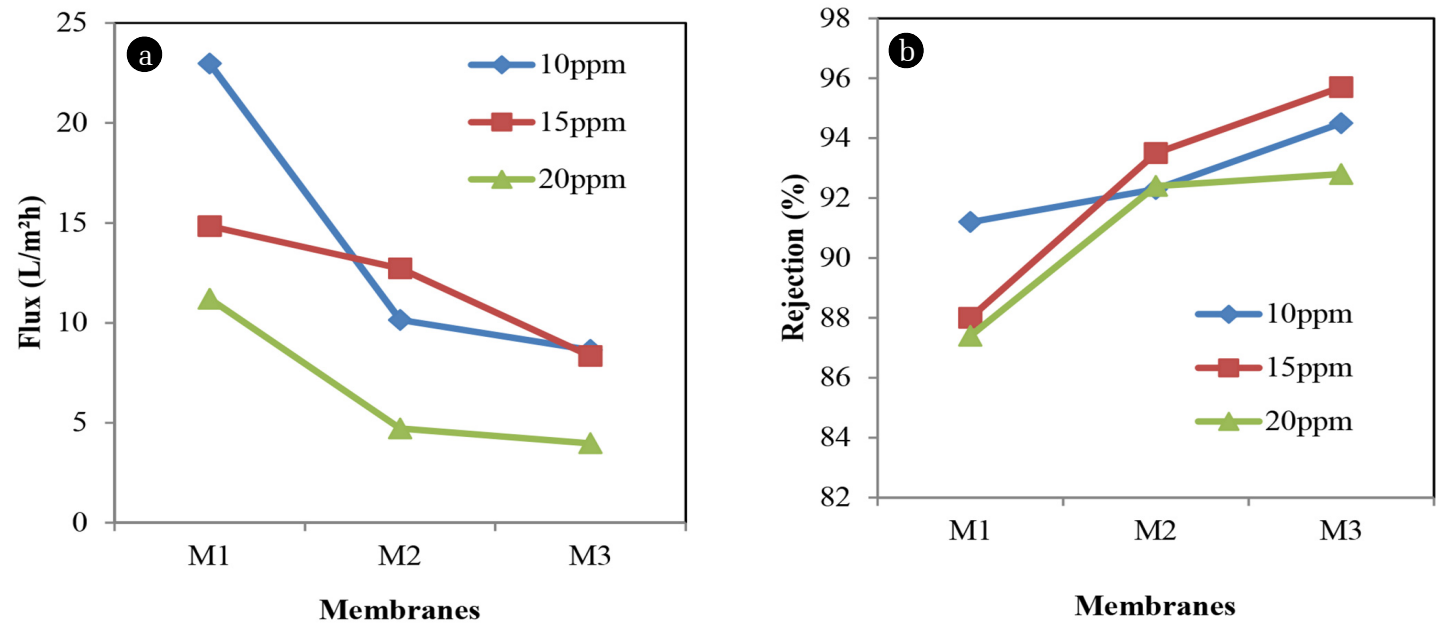

Membranes

Membranes

Fig. 7. (a) Permeation flux; (b) Percentage rejection of Acid orange dye.
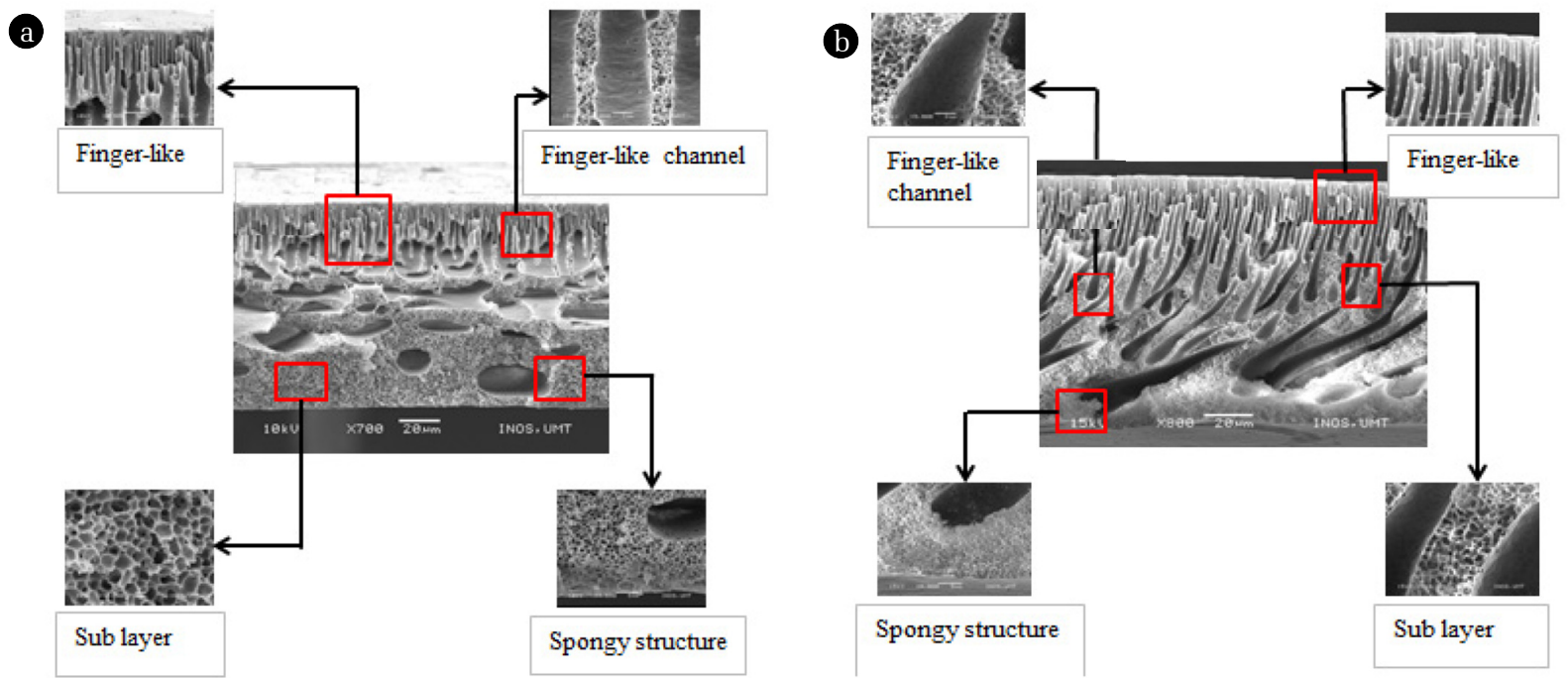

Fig. 8. Cross-sectional image of (a) NF membrane without PEG (b) NF membrane with PEG.

membrane sub-structure. Moreover, macrovoids also has been increased. The same form of membrane support layer existed where PES form thick membrane support layer which makes the membrane more stable. Fig. 8(b) shows denser top layer and thick membrane surface are produced. It was reported that addition of additive could be one of the major factors influencing the membrane performance [10]. The additive is used in order to have an optimal membrane structures that leads to membrane performance-properties. High polymer concentration has shown the least macrovoids formation.

Other researchers found the similar structure in their study that, the addition of PEG 600 as the additive will form a finger-like structure that almost penetrates throughout the membranes and improve the membrane pore interconnectivity [11]. At the 21 wt\% of polymer concentration, it shows good membrane structure with spongy support layer that eases the separation process throughout the membrane.

\section{Conclusions}

From this study, it was found that PES has been confirmed as the promising polymeric material as it showed asymmetric structure via phase inversion technique. Meanwhile, PEG 600 has been known as a better pore former than other additives. It has increased the rejection of dyes up to $99.8 \%$ and influenced the formation of the denser top layer and thick membrane surface as has been seen in a morphological study. Thus, this study significantly contributes to new knowledge and also in treatment wastewater mainly for dyes industry.

\section{Acknowledgments}

The authors wish to express their gratitude to the Research 
Management \& Innovation Centre (RMIC), Universiti Sultan Zainal Abidin (UniSZA) for financing the research project under DPU Research Grant Scheme.

\section{Nomenclature}

$A \quad$ effective membrane area $\left(\mathrm{m}^{2}\right)$

Cf concentration feed $(\mathrm{mg} / \mathrm{mL})$

Cp concentration permeate $(\mathrm{mg} / \mathrm{mL})$

$\hbar$ permeate flux $\left(\mathrm{L} / \mathrm{m}^{2} \mathrm{~h}\right)$

Ppm part per million

$R \quad$ rejection (\%)

$t \quad$ time (h)

$V \quad$ volume of permeate solution collected (L)

\section{References}

1. Garg VK, Kumar R, Gupta R. Removal of malachite green dye from aqueous solution by adsorption using agro-industry waste: A case study of Prosopis cineraria. Dyes Pigm. 2004;62:1-10.

2. Santhi M, Kumar PE, Muralidharan B. Removal of malachite green dyes by adsorption onto activated carbon- $\mathrm{MnO}_{2}$ - nanocomposite-kinetic study and equilibrium isotherm analyses. IOSR J. Appl. Chem. 2015;8:33-41.

3. Wu C, Zhang S, Yang D, Jian X. Preparation, characterization and application of a novel thermal stable composite nano- filtration membrane. J. Membr. Sci. 2009;326:429-434.

4. Otero JA, Lena G, Colina JM, Prádanos P, Tejerina F, Hernández A. Characterisation of nanofiltration membranes: Structural analysis by the DSP model and microscopical techniques. J. Membr. Sci. 2006;279:410-417.

5. Avlonitis SA, Poulios I, Sotiriou D, Pappas M, Moutesidis K. Simulated cotton dye effluents treatment and reuse by nanofiltration. Desalination 2008;221:259-267.

6. Teixeira MR, Rosa MJ, Nyström M. The role of membrane charge on nanofiltration performance. J. Membr. Sci. 2005; 265:160-166

7. Rahimpour A, Madaeni SS, Mansourpanah Y. The effect of anionic, non-ionic and cationic surfactants on morphology and performance of polyethersulfone ultrafiltration membranes for milk concentration. J. Membr. Sci. 2007;296: 110-121.

8. Akbari A, Remigy JC, Aptel P. Treatment of textile dye effluent using a polyamide-based nanofiltration membrane. Chem. Eng. Process. 2002;41:601-609.

9. Petrinić I, Andersen NP, Šostar-Turk S, Le Marechal AM. The removal of reactive dye printing compounds using nanofiltration. Dyes Pigm. 2007;74:512-518.

10. Chakrabarty B, Ghoshal AK, Purkait MK. Effect of molecular weight of PEG on membrane morphology and transport properties. J. Membr. Sci. 2008;309:209-221.

11. Idris A, Zain NM, Noordin MY. Synthesis, characterization and performance of asymmetric polyethersulfone (PES) ultrafiltration membranes with polyethylene glycol of different molecular weights as additives. Desalination. 2007;207:324-339. 